\title{
Correlates of use of withdrawal for contraception among women in Vietnam
}

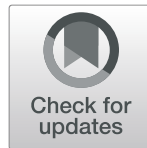

Nghia Nguyen ${ }^{1}$, Linh Nguyen ${ }^{1}$, Hoai Nguyen ${ }^{1}$ and Maria F. Gallo ${ }^{2^{*}}$

\begin{abstract}
Background: Despite its relatively low effectiveness, withdrawal is a common contraceptive practice. In Vietnam, health concerns about hormonal contraception are strong and account for substantial method discontinuation. Given the paucity of evidence on withdrawal, our objective was to identify correlates of using withdrawal among women not desiring pregnancy.

Methods: We conducted a secondary analysis of data from a cross-sectional study of sexually-active adult women attending a public hospital in Hanoi, who did not desire pregnancy. We enrolled a stratified sample of women using the intrauterine device, combination oral contraception, or neither method. Participants completed a questionnaire on demographics and reproductive history and behaviors. We used multinomial logistic regression to evaluate correlates of using a tier 3 contraception method (without withdrawal) and using withdrawal (alone or with a tier 3 method) compared to the referent category of using a tier 1 or 2 method (without withdrawal).

Results: Of the 489 participants in the analysis, 52.3\% reported using tier 1 or 2 method (without withdrawal); $19.8 \%$ reported tier 3 contraception (without withdrawal) and 27.9\% reported using withdrawal (alone or with a tier 3 method). Compared to those using a tier 1 or 2 method, women using withdrawal had lower odds of reporting that avoiding pregnancy was very important or important to them (aOR, $0.4 ; 95 \% \mathrm{Cl}, 0.3-0.7)$. Women using withdrawal had higher odds of reporting that their husband/partner refuses to give them money for household expenses, even when he has the money (aOR, 2.8; 95\% Cl, 1.4-5.6).
\end{abstract}

Conclusions: Women using withdrawal might have less relationship power than nonusers. They also might rely on the practice because they are more ambivalent about pregnancy.

Keywords: Contraception, Vietnam, Pregnancy, unintended, Withdrawal, Women

\section{Background}

The use of withdrawal (coitus interruptus) predates the introduction of modern methods of contraception and remains today a commonly used method for preventing pregnancy [1,2]. Worldwide in 2015, withdrawal was the most effective of any contraceptive method used by an estimated $3.1 \%$ of reproductive-age women who were married or otherwise in-union [2]. Prevalence varied widely by region, with less than $1.0 \%$ reporting relying

\footnotetext{
* Correspondence: gallo.86@osu.edu

${ }^{2}$ Division of Epidemiology, College of Public Health, The Ohio State University, Cunz Hall, 1841 Neil Avenue, Columbus, OH 433210, USA Full list of author information is available at the end of the article
}

on withdrawal in Southern Africa, Eastern Asia, Western Europe, and Eastern Africa (0.4, 0.6, 0.6 and 0.8\%, respectively). In contrast, $12.9 \%$ of women in Southern Europe and $15.1 \%$ in Western Asia reported withdrawal to be the most effective contraceptive method that they currently used.

Prevalence figures for withdrawal, though, are sensitive to methods of posing the question and calculating the outcome. First, when asked to report on their contraceptive method use, survey respondents might fail to consider withdrawal as a method unless they are prompted to do so [3-5]. Furthermore, social desirability bias might prevent their reporting reliance on a traditional 
method to health care providers or researchers [1]. Also, while some use withdrawal alone, withdrawal is often combined with other method(s). For example, couples might use withdrawal routinely with male condoms or periodic abstinence to improve the overall protection for the act [6], or they might use withdrawal to compensate for inconsistent adherence to another method. Some report using withdrawal in place of condoms with established partners whom they perceive to be at low risk of HIV or other sexually transmitted infections (STIs) $[5,7]$ while others might use withdrawal as a result of misconceptions about the method's ability to protect against HIV/STI acquisition [8]. Despite the common practice of mixing methods, prevalence estimates often are calculated for the single most effective method used by the participant. These measures, therefore, will not account for many withdrawal users.

Withdrawal is less effective than many other contraceptive methods, with a one-year, probability of pregnancy during typical use of $20 \%$ [9]. In comparison, the one-year typical failure rate for oral contraception is $7 \%$. The estimated effectiveness of withdrawal, though, is based on data from the U.S., and the frequency of failure could be expected to differ between settings, in part because the way that withdrawal is practiced could vary substantially between different cultures [10]. Even if performed perfectly at every act, withdrawal theoretically carries a risk of pregnancy because pre-ejaculatory fluid contains sperm [11].

Despite its lower effectiveness compared to modern methods of contraception, withdrawal offers a number of advantages, including its lack of cost and other issues of access. Concerns about side effects and health risks from modern methods of contraception constitute a major barrier to contraception use [12], and some report preferring withdrawal for its lack of health effects, greater intimacy compared to condoms, and "naturalness." The "naturalness" or non-medical status also is cited as a benefit by those who oppose the use of contraception for religious or cultural beliefs [13]. Finally, although some men describe reduced sexual pleasure from requiring the man to pull out before ejaculation, other men perceive withdrawal as more pleasurable than experiencing the loss in sensation from wearing a condom [14].

Concerns about side effects and health risks from contraception appear to be particularly strong in Southeast Asia, accounting for $36 \%$ of non-use among women with unmet need for contraception [12]. These concerns also can lead to method discontinuation; for example, 19\% of IUD users in a study conducted in six facilities in Vietnam had discontinued by 24 months, and almost half (49\%) of those discontinuing the IUD cited health concerns as the primary reason [15]. Thus, withdrawal might be an acceptable alternative among women in Vietnam; however, evidence on those using withdrawal is sparse. We conducted an exploratory analysis to identify correlates of withdrawal use (either alone or with another relatively loweffective method) among women in Vietnam who did not desire pregnancy.

\section{Methods}

We conducted a secondary analysis of data from a crosssectional study of 500 adult women, 18 to 45 years of age, who were attending the obstetrics-gynecology department in a large public hospital in Hanoi, Vietnam between November 2017 to September 2018. The study enrolled a stratified, convenience sample of women who currently were using 1) the intrauterine device (IUD); 2) combination oral contraception (COC); or 3) were not using, or seeking to start use of, either method. The primary aim was to evaluate a new approach for measuring women's beliefs about contraception, and these findings will be reported elsewhere. Participants had to have least a minimal level of literacy and comfort with a computer and be sexually active, which we defined as at least 1 penile-vaginal act in past month. Exclusion criteria consisted of being pregnant, breastfeeding, or desiring pregnancy in the next year. Women provided written consent before enrolling. Institutional review boards at The Ohio State University and the Hanoi School of Public Health approved the study.

Female study interviewers administered a questionnaire in REDCap, which is an electronic data capture tool for collecting and managing study data. The questionnaire covered participant demographics and reproductive, sexual and contraceptive history and related behaviors. The question on current contraception use was as follows: "Are you using any of these methods currently? Pill, IUD, injections, implant, diaphragm, foam, jelly, male partner sterilization, rhythm or periodic abstinence, male condom, female condom, withdrawal, none or other." All responses were recorded.

Because few women reported using no method $(n=9)$ or reported using withdrawal along with a tier $1(n=1)$ or tier 2 method $(n=1)$, we excluded these 11 women from the present analysis. Thus, the analysis was based on 489 participants. We first report the numbers of women who were using each type of contraceptive method stratified by use of withdrawal. We then evaluated potential correlates of contraceptive method use, using three categories: 1) tier 1 or 2 contraceptive method without withdrawal use; 2) tier 3 method without withdrawal use; and 3) any withdrawal (alone or with a tier 3 method). Tier classifications are based on the number of expected pregnancies per 100 women per year using the method with $<1$ pregnancy expected for 
tier 1 methods, 2-7 pregnancies for tier 2 methods, and 18 or greater for tier 3 methods [16].

Given the lack of research on the practice of withdrawal in Southeast Asia, and Vietnam in particular, and given the exploratory nature of this analysis, we evaluated a broad range of potential correlates in the unadjusted analysis. These consisted of the following demographic variables: age, residence (city vs. town or rural area), highest level of education completed (upper secondary or less vs. higher) and monthly household income $(<15,000,000$ Vietnamese dong, which was equivalent to about 650 U.S. dollars vs. higher). We also evaluated the following partner and reproductive-related factors history: husband or partner ever refuses to give money for household expenses even if he has the money (yes vs. no or no husband or partner); sexual frequency (at least weekly vs less often); health provider has discussed contraception (yes vs. no); mother or sister has used an IUD or COC (yes vs. no); perception of IUD naturalness ("very natural" or "mostly natural" vs. "mostly unnatural" or "very unnatural"); perception of COC naturalness ("very natural" or "mostly natural" vs. "mostly unnatural" or "very unnatural"); importance of avoiding pregnancy ("very important" or "important" vs. "neutral / no opinion" or "not very important") and history of forced sex (yes vs. no). Many of these factors (i.e., age, residence, education, income, financial empowerment and sexual coercion) were selected because they were previously identified as correlate of withdrawal use; the remaining were selected for evaluation in this exploratory analysis based on literature suggesting that women use withdrawal because they do not find other methods accessible or acceptable [7, 17-23].

We used multinomial logistic regression to identify correlates of using a tier 3 method (without withdrawal) and using any withdrawal (alone or with tier 3 method) compared to the referent category of using a tier 1or 2 contraceptive method (without withdrawal). All correlates that varied by method use in unadjusted multinomial analysis, based on a $p$-value of $\leq 0.25$, were included in the final adjusted multinomial regression model [24]. We conducted analyses in SAS, version 9.2 (SAS Institute Inc., Cary, North Carolina).

\section{Results}

Participants $(n=489)$ reported using tier 1 or 2 method without withdrawal $(52.3 \%$; most often IUD or COC use); tier 3 contraception without withdrawal (19.8\%) or withdrawal alone or with a tier 3 method (27.9\%) (Table 1). Only 32 women relied on withdrawal alone; most using withdrawal also used another method, most commonly male condoms or rhythm or periodic abstinence. Participants were mostly married (96.5\%), were urban (90.4) and of Kinh ethnicity (94.9\%). The mean
Table 1 Contraceptive method by withdrawal use among sexually-active women not desiring pregnancy, Hanoi, Vietnam $(N=489)$

\begin{tabular}{ll}
\hline Contraceptive method $^{\text {a }}$ & No. \\
\hline Tier 1 or 2 method, no withdrawal & 5 \\
Implant & 128 \\
Intrauterine device & 1 \\
Tubal ligation & 1 \\
Injection & 125 \\
Oral contraception & \\
Tier 3, no withdrawal & 88 \\
Male condom & 5 \\
Female condom & 0 \\
Foam, jelly, film & 13 \\
Rhythm, periodic abstinence & \\
Withdrawal with or without tier 3 method & 81 \\
Male condom & 3 \\
Female condom & 1 \\
Foam, jelly, film & 70 \\
Rhythm, periodic abstinence & 32 \\
Withdrawal only &
\end{tabular}

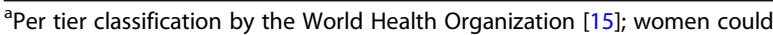
report multiple contraception methods

age of participants was 34.0 years (standard deviation, 5.2; range). Age terciles were approximately $21-31,32-$ 36 and $37-45$ years.

In the unadjusted analyses, 5 factors were associated with withdrawal (at the higher $p$-value of 0.25 for this initial assessment): age, husband/partner ever refuses to give money for household expenses even if he has the money, health provider has discussed contraception, importance of avoiding pregnancy, and history of forced sex (Table 2). The adjusted multinomial regression model, which was fitted with these 5 variables, showed 2 factors to be associated with using withdrawal (Table 3) compared to using a tier 1 or 2 method. First, women using withdrawal had higher odds of reporting that their husband or partner refuses to give them money for household expenses, even when he has the money (aOR, 2.8 ; $95 \% \mathrm{CI}, 1.4-5.6)$. Second, women using withdrawal also had lower odds of reporting that avoiding pregnancy was very important or important to them (aOR, $0.4 ; 95 \% \mathrm{CI}, 0.3-0.7)$.

\section{Discussion}

Among the study population of sexually-active women in Hanoi who did not desire pregnancy in the next year, two factors were associated with use of withdrawal: reporting that one's husband or partner ever refuses to give money for household expenses even if he has the 
Table 2 Participant demographics, characteristics and behaviors by contraceptive method use among sexually-active women not desiring pregnancy, Hanoi, Vietnam ( $N=489)$

\begin{tabular}{|c|c|c|c|c|c|c|c|}
\hline & \multicolumn{2}{|c|}{$\begin{array}{l}\text { Tier } 1 \text { or } 2 \text { method, no } \\
\text { withdrawal }(N=257)\end{array}$} & \multicolumn{2}{|c|}{$\begin{array}{l}\text { Tier } 3 \text { method, no } \\
\text { withdrawal }(N=97)\end{array}$} & \multicolumn{2}{|c|}{$\begin{array}{l}\text { Withdrawal only or with Tier } 3 \\
\text { method }(N=135)\end{array}$} & \multirow[t]{2}{*}{$p$-value } \\
\hline & No. & $(\%)$ & No. & $(\%)$ & No. & $(\%)$ & \\
\hline Age, mean (standard deviation) & 34.5 & $(4.9)$ & 32.9 & $(5.5)$ & 33.9 & (5.6) & 0.03 \\
\hline \multicolumn{8}{|l|}{ Residence } \\
\hline City & 235 & $(91.4)$ & 87 & $(89.7)$ & 120 & $(88.9)$ & \multirow[t]{2}{*}{0.69} \\
\hline Town or rural area & 22 & (8.6) & 10 & $(10.3)$ & 15 & $(11.1)$ & \\
\hline \multicolumn{8}{|l|}{ Highest level of education completed } \\
\hline Upper secondary or less & 64 & $(24.9)$ & 27 & $(28.1)$ & 29 & $(21.5)$ & \multirow[t]{2}{*}{0.51} \\
\hline Higher & 193 & $(75.1)$ & 69 & (71.9) & 106 & $(78.5)$ & \\
\hline \multicolumn{8}{|l|}{ Monthly household income } \\
\hline$<15,000,000$ Vietnamese dong & 54 & $(23.7)$ & 15 & $(17.4)$ & 26 & $(21.0)$ & \multirow[t]{2}{*}{0.48} \\
\hline$\geq 15,000,000$ Vietnamese dong & 174 & $(76.3)$ & 71 & $(82.6)$ & 98 & (79.0) & \\
\hline \multicolumn{8}{|c|}{ Husband/partner ever refuse to give money for household expenses even if has money } \\
\hline Yes & 18 & (7.0) & 9 & (9.3) & 25 & $(18.5)$ & \multirow[t]{2}{*}{$<0.01$} \\
\hline No or not applicable & 239 & $(93.0)$ & 88 & $(90.7)$ & 110 & $(81.5)$ & \\
\hline \multicolumn{8}{|l|}{ Sexual frequency } \\
\hline At least weekly & 215 & $(87.4)$ & 77 & $(83.7)$ & 108 & $(82.4)$ & \multirow[t]{2}{*}{0.39} \\
\hline Less than weekly & 31 & $(12.6)$ & 15 & $(16.3)$ & 23 & $(17.6)$ & \\
\hline \multicolumn{8}{|l|}{ Health provider has discussed contraception } \\
\hline Yes & 158 & $(61.7)$ & 54 & $(56.3)$ & 72 & $(53.3)$ & \multirow[t]{2}{*}{0.25} \\
\hline No & 98 & $(38.3)$ & 42 & $(43.8)$ & 63 & $(46.7)$ & \\
\hline \multicolumn{8}{|l|}{ Mother or sister used the IUD or COC } \\
\hline Yes & 193 & $(75.4)$ & 67 & $(69.1)$ & 96 & $(71.1)$ & \multirow[t]{2}{*}{0.42} \\
\hline No & 63 & $(24.6)$ & 30 & $(30.9)$ & 39 & $(28.9)$ & \\
\hline \multicolumn{8}{|l|}{ Perception of IUD naturalness } \\
\hline Very natural, mostly natural & 154 & $(60.9)$ & 48 & $(52.2)$ & 80 & $(60.6)$ & \multirow[t]{2}{*}{0.32} \\
\hline Mostly unnatural, very unnatural & 99 & $(39.1)$ & 44 & $(47.8)$ & 52 & (39.4) & \\
\hline \multicolumn{8}{|l|}{ Perception of COC naturalness } \\
\hline Very natural, mostly natural & 155 & $(60.6)$ & 54 & $(55.7)$ & 84 & $(64.1)$ & \multirow[t]{2}{*}{0.43} \\
\hline Mostly unnatural, very unnatural & 101 & $(39.5)$ & 43 & $(44.3)$ & 47 & (35.9) & \\
\hline \multicolumn{8}{|l|}{ Importance of avoiding pregnancy } \\
\hline Very important, important & 224 & $(87.5)$ & 79 & $(83.2)$ & 104 & $(77.0)$ & \multirow[t]{2}{*}{0.03} \\
\hline Neutral/no opinion, not very important & 32 & $(12.5)$ & 16 & $(16.8)$ & 31 & $(23.0)$ & \\
\hline \multicolumn{8}{|l|}{ History of forced sex } \\
\hline Yes & 22 & (8.6) & 11 & $(11.5)$ & 20 & $(15.0)$ & \multirow[t]{2}{*}{0.15} \\
\hline No & 234 & $(91.4)$ & 85 & $(88.5)$ & 113 & $(85.0)$ & \\
\hline
\end{tabular}

COC combination oral contraception, IUD intrauterine device

aper tier classification by the World Health Organization [15]

money, and not perceiving avoiding pregnancy in the next year as very important or important. A previous study on the quality of family planning in Vietnam found that use of any withdrawal appeared to be higher among those of Kinh ethnicity versus those of other ethnicities (12.2\% versus $8.8 \%$, respectively) [25]. However, we could not evaluate the role of ethnicity because our study was almost exclusively comprised of women of Kinh ethnicity. Age also previously was found to be positively associated with any withdrawal use: $11.6 \%$ of women 20-49 years of age reported using any withdrawal compared to $5 \%$ of women 15-19 years [25]. In contrast, we did not find evidence suggesting increased use of withdrawal among older women. 
Table 3 Correlates of use tier 3 method (no withdrawal) or use of withdrawal (only or with Tier 3 method) compared to use of a tier 1 or 2 method (no withdrawal) a among sexually-active women not desiring pregnancy, Hanoi, Vietnam $(N=489)^{b}$

\begin{tabular}{|c|c|c|c|c|}
\hline & \multicolumn{2}{|c|}{ Tier 3 method, no withdrawal } & \multicolumn{2}{|c|}{ Withdrawal only or with Tier 3 method } \\
\hline & $\mathrm{aOR}$ & $(95 \% \mathrm{Cl})$ & $\mathrm{aOR}$ & $(95 \% \mathrm{Cl})$ \\
\hline Age in years & 1.0 & $(0.9,1.0)$ & 1.0 & $(1.0,1.0)$ \\
\hline \multicolumn{5}{|c|}{ Husband/partner ever refuse to give money for household expenses, even when has money } \\
\hline Yes & 1.4 & $(0.6,3.3)$ & 2.8 & $(1.4,5.6)$ \\
\hline No or not applicable & Ref & & Ref & \\
\hline \multicolumn{5}{|l|}{ Health provider has discussed contraception } \\
\hline Yes & 0.8 & $(0.5,1.2)$ & 0.7 & $(0.4,1.0)$ \\
\hline No & Ref & & Ref & \\
\hline \multicolumn{5}{|l|}{ Importance of avoiding pregnancy } \\
\hline Very important, important & 0.7 & $(0.4,1.1)$ & 0.4 & $(0.3,0.7)$ \\
\hline Neutral / no opinion, not very important & Ref & & Ref & \\
\hline \multicolumn{5}{|l|}{ History of forced sex } \\
\hline Yes & 1.3 & $(0.6,3.0)$ & 1.7 & $(0.8,3.4)$ \\
\hline No & Ref & & Ref & \\
\hline
\end{tabular}

$\mathrm{COC}=$ combination oral contraception; IUD = intrauterine device

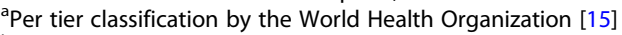

${ }^{b}$ Results are from full multinomial regression model that includes all variables in the table with Tier 1 or 2 method without withdrawal as the referent

Withdrawal appeared to be a common practice in the study population. Among women using withdrawal in the present study, most also reported using either male condoms or a fertility-based awareness method. We did not collect data, though, on whether the multiple methods were combined during single acts, whether women switched between methods for different acts, or the frequency of use or adherence to the use of the methods. Future research could seek to better understand the patterns of withdrawal use within individual women and the reasons for using withdrawal alone versus in combination with other methods.

According to data from the nationally-representative Multiple Indictor Cluster Surveys conducted among reproductive-age, married or cohabiting women in Vietnam, only $5.4 \%$ of women in 2014 reported using withdrawal only to delay or prevent pregnancy [17]. In a more recent study of family planning services conducted in 2015 in Vietnam, the prevalence of any withdrawal use (i.e., alone or combined with other methods) was $11.5 \%$ among married women [25]. This figure differed by region, ranging from $7 \%$ of women in the Red River Delta region to $17.7 \%$ in the North and South Central Coast region.

Future research should seek to address women's concerns about the safety of highly-effective contraception $[12,15]$. At the same time, efforts also should focus on ensuring that couples who opt to use withdrawal receive counseling on the concomitant use of other methods as a harm reduction method for reducing the risk of unintended pregnancy. Although not statistically significant, lower proportions of women using withdrawal in the present study reported that a health provider discussed contraception with them compared to non-users of withdrawal. Withdrawal users should be counseled on the method's lack of protection against HIV/STI transmission. Because withdrawal users may not perceive withdrawal to be a legitimate method of contraception, they may hesitate to discuss the method during contraceptive counseling with their health care provider [18]. Providers should questions patients specifically about the method rather than make assumptions about its nonuse.

Recent studies have suggested that because most participants combined withdrawal with a hormonal or longacting method or condoms, withdrawal users might actually represent a subset of individuals who are more proactively protecting themselves against pregnancy compared to nonusers of withdrawal [7, 19]. However, we cannot assess this in the present study as we do not know whether women who reported multiple methods used them as dual protection or whether they switched between two methods on a per act basis. Unlike the earlier U.S. study, few $(n=2)$ women in the parent study used for the present analysis reported using withdrawal and a tier 1 or 2 method. Thus, achieving high contraceptive protection did not appear to be an important motivation for withdrawal use among women in the present study.

Study limitations include limited generalizability as the study sample was a relatively homogeneous group of women - in terms of ethnicity, urbanicity and marital 
status - attending a single site in Hanoi. Study findings might not apply more broadly to women in Vietnam or to those at highest risk of unintended pregnancy in Vietnam [26]. Furthermore, the cross-sectional nature of this secondary analysis does not allow for establishing a causal relationship between the correlates identified and the practice of withdrawal. Finally, because we selected on contraceptive method status (IUD, COC versus neither) among a convenience sample of women attending a single facility, our results cannot be used to estimate the overall prevalence of withdrawal use among women in Vietnam. Strengths of the analysis include the collection of detailed information on participant characteristics and behaviors that were possibly related to withdrawal in a population that lacks previous research on this topic.

\section{Conclusion}

Study findings indicate that withdrawal might be more common among women with lower relationship power (as evidenced by lack of ability to access funds from their partner). Although the study was restricted to women who reported not desiring pregnancy in the next year, women varied in the degree to which they perceived avoiding pregnancy to be important. Findings suggest that a subset of women might choose to rely on the lesseffective method of withdrawal because of their ambivalence about future pregnancy. Future research on withdrawal should determine couple's motivation for using withdrawal in order to separate out subgroups that likely differ in important ways.

\author{
Abbreviations \\ aOR: Adjusted odds ratio; Cl: Confidence interval; COC: Combination oral \\ contraception; IUD: Intrauterine device; OR: Odds ratio; STI: Sexually \\ transmitted infections
}

\section{Acknowledgements}

Not applicable.

\section{Authors' contributions}

NN and MG developed the study protocol. LN and HN led the data collection. MG conducted the analysis and drafted the manuscript. All authors were involved in revising the manuscript and approved the final manuscript.

\section{Funding}

This work was supported by the Bill \& Melinda Gates Foundation [OPP1171894] and the National Center for Advancing Translational Sciences [UL1TR001070]. The content is solely the responsibility of the authors and does not necessarily represent the official views of the Bill \& Melinda Gates Foundation, the National Center for Advancing Translational Sciences, or the National Institutes of Health.

\section{Availability of data and materials}

The study dataset is available from the corresponding author following institutional approvals.
Ethics approval and consent to participate

Institutional review boards at The Ohio State University and the Hanoi School of Public Health approved the study, and women provided written consent before enrolling.

\section{Consent for publication}

Not applicable.

\section{Competing interests}

The authors have no competing interests.

\section{Author details}

${ }^{1}$ Department of Obstetrics and Gynecology, Vinmec International Hospital, 458 Minh Khai, Hanoi, Vietnam. '2Division of Epidemiology, College of Public Health, The Ohio State University, Cunz Hall, 1841 Neil Avenue, Columbus, $\mathrm{OH}$ 433210, USA.

Received: 17 September 2019 Accepted: 16 April 2020

Published online: 29 April 2020

\section{References}

1. Rogow D, Horowitz S. Withdrawal: a review of the literature and an agenda for research. Stud Fam Plan. 1995;26:140-53.

2. United Nations. Department of Economic and Social Affairs, Population Division. Trends in Population Use Worldwide 2015. New York: United Nations; 2015.

3. Jones RK, Fennell J, Higgins JA, Blanchard K. Better than nothing or savvy risk-reduction practice? The importance of withdrawal. Contraception. 2009; 79:407-10.

4. Rossier C, Senderowicz L, Soura A. Do natural methods count? Underreporting of natural contraception in urban Burkina Faso. Stud Fam Plan. 2014;45:171-82.

5. Arteaga S, Gomez AM. "Is that a method of birth control?" A qualitative exploration of young women's use of withdrawal. J Sex Res. 2016;53:626-32.

6. De Visser R. Delayed application of condoms, withdrawal and negotiation of safer sex among heterosexual young adults. AIDS Care. 2004;16:315-22.

7. Jones RK, Lindberg LD, Higgins JA. Pull and pray or extra protection? Contraceptive strategies involving withdrawal among US adult women. Contraception. 2014;90:416-21.

8. Donovan B. The repertoire of human efforts to avoid sexually transmissible diseases: past and present. Part 2: strategies used during or after sex. Sex Transm Infect. 2000;76:88-93.

9. Trussell J, Aiken ARA. Contraceptive efficacy. In: Hatcher RA, Nelson AL, Trussell J, Cwiak C, Cason P, Policar MS, et al., editors. Contraceptive technology. 21st ed. New York: Ayer Company Publishers, Inc; 2018.

10. Sinai I. Re: better than nothing or savvy risk-reduction practice: the important of withdrawal. Contraception. 2010;82:391-2.

11. Killick SR, Leary C, Trussell J, Guthrie KA. Sperm content of pre-ejaculatory fluid. Hum Fertil. 2011;14:48-52.

12. Sedgh $G$, Hussain R. Reasons for contraceptive nonuse among women having unmet need for contraception in developing countries. Stud Fam Plan. 2014;45:151-69.

13. Cebeci Save D, Erbaydar T, Kalaca S, Harmanci H, Cali S, Karavus M. Resistance against contraception or medical contraceptive methods: a qualitative study on women and men in Istanbul. Eur J Contracept Reprod Health Care. 2004;9:94-101.

14. Ortayli N, Bulut A, Ozugurlu M, Cokar M. Why withdrawal? Why not withdrawal? Men's perspectives. Reprod Health Matters. 2005;13:164-73.

15. Park MH, Nguyen TH, Ngo TD. Dynamics of IUD use in Vietnam: implications for family planning services at primary health care level. Int J Womens Health. 2011;3:429-34.

16. World Health Organization, Johns Hopkins, United States Agency for International Development. Family planning: a global handbook for providers. 3rd ed; 2018.

17. General Statistics Office and UNICEF. Viet Nam Multiple Indicator Cluster Survey 2014, Final report. Hanoi; 2015.

18. Whittaker PG, Merkh RD, Henry-Moss D, Hock-Long L. Withdrawal attitudes and experiences: a qualitative perspective among young urban adults. Perspect Sex Reprod Health. 2010;42:102-9. 
19. Higgins JA, Wang Y. Which young adults are most likely to use withdrawal? The importance of pregnancy attitudes and sexual pleasure. Contraception. 2015;91:320-7.

20. Cindoglu D, Sirkeci I, Sirkeci RF. Determinants of choosing withdrawal over modern contraceptive methods in Turkey. Eur J Contracept Reprod Health Care. 2008;13:412-21.

21. Wiebe ER, Janssen PA, Henderson A, Fung I. Ethnic Chinese women's perceptions about condoms, withdrawal and rhythm methods of birth control. Contraception. 2004;69:493-6.

22. Winetrobe H, Rhoades H, Barman-Adhikari A, Cederbaum J, Rice E, Milburn N. Pregnancy attitudes, contraceptive service utilization, and other factors associated with Los Angeles homeless youths' use of effective contraception and withdrawal. J Pediatr Adolesc Gynecol. 2013;26:314-22.

23. Woods JL, Hensel DJ, Fortenberry JD. Contraceptive withdrawal in adolescents: a complex picture of usage. J Pediatr Adolesc Gynecol. 2009;22: 233-7.

24. Hosmer D, Lemeshow S, Sturdivant R. Model building strategies and methods for logistic regression. Applied logistic regression. Hoboken: Wiley; 2013. p. 91-142.

25. Vietnam Ministry of Health and UNFPA. Study on the Quality of Family Planning Services in Vietnam. Hanoi; 2017.

26. Asad S, Hebert C, Andridge R, Nguyen N, Gallo MF. Changes in the use of effective and long-acting reversible contraception in Vietnam. Contraception. 2019:99:165-9.

\section{Publisher's Note}

Springer Nature remains neutral with regard to jurisdictional claims in published maps and institutional affiliations.

Ready to submit your research? Choose BMC and benefit from:

- fast, convenient online submission

- thorough peer review by experienced researchers in your field

- rapid publication on acceptance

- support for research data, including large and complex data types

- gold Open Access which fosters wider collaboration and increased citations

- maximum visibility for your research: over $100 \mathrm{M}$ website views per year

At BMC, research is always in progress.

Learn more biomedcentral.com/submissions 